Esta revista forma parte del acervo de la Biblioteca Jurídica Virtual del Instituto de Investigaciones Jurídicas de la UNAM

\title{
La regulación partidista en México. Pertinencia, propósitos y contenidos mínimos para una ley de partidos
}

\section{Rosa María Mirón Lince*}

\section{Sumario:}

I. Los partidos, una presencia necesaria

II. El debate sobre la regulación

III. Contenidos mínimos de una ley reglamentaria

IV. Conclusiones

V. Bibliografía

VI. Anexo

* Doctora en Ciencia Política; profesora investigadora en la Facultad de Ciencias Políticas y Sociales de la UNAM; integrante del Sistema Nacional de Investigadores; responsable del proyecto PAPIIT IN303012 "Procesos electorales, reformas legales y sistema de partidos en el gobierno de Felipe Calderón”. 
A pesar de las importantes funciones que desempeñan como elementos centrales de la democracia representativa, los partidos políticos atraviesan por una crisis de legitimidad que deriva de una percepción ciudadana, acerca de que se han apartado de los fines para los cuales fueron creados; se acusa a los partidos de estar más comprometidos con los intereses de sus dirigentes que con los de la sociedad. En México, se advierte que se han convertido en maquinarias burocráticas que florecen al amparo de los recursos que les inyecta el Estado mientras se apartan de la comunicación con la sociedad. Así, se mira con preocupación, cómo los partidos han dejado de ser puentes entre la población y el poder político para convertirse en ínsulas donde la clase política se reparte cargos y privilegios.

Por ello, resulta necesaria una mayor atención a los actos de los partidos políticos que bien podría concretarse en una ley de partidos hasta hoy ausente y cuya pertinencia se encuentra, por lo menos, en las siguientes razones:

- Los partidos, como entes financiados por el Estado, deben manejar con transparencia los recursos que reciben.

- La utilidad de fomentar la democracia al interior de los partidos ya que son organizaciones cuyos objetivos tienden a una forma de vida democrática.

- La necesidad de armonizar las leyes sobre partidos y evitar lagunas en los temas de mayor interés para la sociedad.

- La conveniencia de hacer coincidir los principios y valores democráticos al interior de los partidos.

A pesar de que en nuestro país los partidos políticos se inscriben en una regulación maximalista ya que se regulan tanto constitucionalmente como en una ley reglamentaria, a saber, el Código Federal de Instituciones y Procedimientos Electorales (Cofipe), existen temas que son perfectibles y a los cuales se ha dejado sin una clara definición, lo que provoca el fortalecimiento de los dirigentes en detrimento de las bases. Por ejemplo, en lo relativo a los derechos de postulación como candidato, en los hechos existe una tendencia hacia la oligarquización que impide que cualquier militante pueda acceder a dicha posición.

En adelante, examinaremos las características de los partidos y del sistema de partidos para señalar las particularidades del caso mexicano. Posteriormente nos aproximaremos al debate sobre la regulación 
de partidos así como a los contenidos mínimos que debería abordar una ley de partidos para México.

\section{Los partidos, una presencia necesaria}

La teoría clásica de los partidos define a estas entidades como organizaciones de ciudadanos que compiten a través de las elecciones para acceder a cargos de gobierno y establecer su agenda legislativa y de gobierno (Duverger, 1976; Sartori, 1993; Ware, 1996; Weber, 1994). La agenda partidista se integra por las demandas, propuestas e intereses sociales que aglutinan y organizan.

Para el estudio de los partidos políticos es preciso ubicarlos dentro de un sistema en el que interactúan con otros entes de la vida política. Varias son las clasificaciones que se proponen para identificar a los diferentes sistemas de partidos, pero todas ellas están asociadas de manera estrecha e indisoluble a la del sistema de partidos en el cual se desenvuelven. Dieter Nohlen (1994) define al sistema de partidos como "la composición estructural de la totalidad de partidos políticos en el Estado". De acuerdo con este autor, los distintos teóricos coinciden en estudiar a dichos sistemas con base en el número de partidos, su tamaño, la distancia ideológica entre ellos, sus pautas de interacción, su relación con la sociedad o los grupos sociales, así como su actitud frente al sistema político.

Los sistemas de partidos forman parte, a su vez, del sistema político. Las reglas de la competencia electoral, las garantías para el ejercicio de las libertades políticas, el nivel de polarización política en la sociedad, la diversidad cultural e ideológica en la ciudadanía, son algunos de los elementos del sistema político que influyen en su conformación. Éstos han sido analizados y clasificados en varios textos clásicos de la ciencia política. Maurice Duverger (1976) los ordena según el número y describe sistemas de partido único, bipartidistas y multipartidistas; Joseph La Palombara y Werner (1969) proponen distinguir entre partidos competitivos y no competitivos; Giovanni Sartori (2005) atiende tanto a criterios cualitativos como cuantitativos al proponer una clasificación gradual que incluye sistemas de partido único, de partido dominante, de partido hegemónico, bipartidistas, de pluralismo limitado, de pluralismo polarizado y de atomización partidista.

En el fondo, todas las clasificaciones identifican una relación estrecha entre el sistema de partidos y el sistema político. En los regímenes 
no democráticos la lucha por el poder político no transcurre a través de la competencia partidista en elecciones libres y la posibilidad de alternancia en el Poder Ejecutivo está excluida (Crespo, 1991). En efecto, la ausencia de competencia política se considera una señal negativa que advierte la falta de garantías para la diversidad política, el pluralismo y la libre asociación. ${ }^{1}$

Sin embargo, la existencia de un gran número de partidos es considerada un signo inquietante. En la práctica, la atomización de los partidos políticos suele ir asociada a la ausencia de representación de intereses nacionales, identidades políticas organizadas o corrientes ideológicas estructuradas. Por el contrario, la proliferacion de partidos se vincula a la existencia de clientelas étnicas, tribales o regionales demasiado específicas para establecer un gobierno o un congreso estable. Es más, la relativa facilidad para crear partidos políticos incentiva la formación de las llamadas microempresas electorales (Pizarro, 2002).

En términos funcionales, las obras de Sartori (1993), La Palombara (1969) y Duverger (1976) señalan la idoneidad de contar con una cantidad moderada de partidos estables, cohesionados y con un grado de institucionalización que sea expresión de aspectos como su antigüedad, estructura, tamaño e ideología. Un sistema de partidos plural sólo puede coexistir con un sistema político donde las elecciones sean el medio por el cual se decide quiénes integrarán los órganos de gobierno y representación, con una sociedad abierta, y con un Estado de derecho en el que todos los ciudadanos sean portadores de un conjunto de derechos y obligaciones (Sartori, 1993).

La búsqueda de un entorno partidista plural y competitivo es esencial para la funcionalidad de la democracia electoral. En este sentido, la ingeniería institucional ha sido un elemento por medio del cual la regulación de las elecciones y los partidos pueden ser compatibles con el modelo de democracia representativa. Sartori (1999) estudia la ingeniería institucional aplicada a los sistemas electorales como una forma de influir en la configuración de los sistemas de partidos, pero Pierre Calame (2006) considera que los propósitos del diseño institucional pueden ir más a fondo con el fin de "crear estructuras y culturas

1 Dieter Nohlen (1992) señala que en el estudio de las relaciones entre el sistema político, el electoral y el de partidos existen visiones generalizadas, que no siempre se confirman al analizar la evidencia empírica, pero que permanecen en la cultura académica, muchas veces a pesar de que sus propios autores las han corregido y reformulado al paso de los años. 
capaces de manejar las relaciones entre los desafíos, entre los actores, entre los niveles de gobernanza”.

La ingeniería institucional es "el arte de concebir instituciones cuya 'lógica profunda' vaya en el mismo sentido que los objetivos perseguidos" (Calame, 2006), esto es, cuyas estructuras y procesos incentiven el cumplimiento de los propósitos para los cuales fueron creadas las instituciones y eviten en lo posible la desviación de tales propósitos. Este autor propone, además, que el factor humano se considere el eje del diseño institucional y no su límite, a través de una actividad formativa en valores éticos y profesionales, con el fin de promover que las acciones personales se dirijan al cumplimiento de los fines institucionales.

Así pues, los arreglos del diseño institucional han de dirigirse a fortalecer el cumplimiento de los fines que la propia Constitución reconoce para los partidos políticos. Encargados de articular las opiniones de ciudadanos y organizaciones para transformarlas en propuestas de gobierno y legislación, de organizar la participación política, además de conducirla por los canales de acción y participación institucionales, los partidos políticos son enlaces e intermediarios permanentes entre la población y el Estado, pero son también el medio por el cual los individuos se incorporan a la clase política (González Oropeza y Báez Silva, 2010).

Éste es, precisamente, el sentido que da el artículo 41 constitucional, cuando define a los partidos políticos como "entidades de interés público" que tienen como fines "promover la participación del pueblo en la vida democrática, contribuir a la representación nacional y como organizaciones de ciudadanos, hacer posible el acceso de éstos al ejercicio del poder público" (CPEUM, artículo 41).

Al considerarlos entidades de interés público, se asume que los partidos políticos "son colectividades pertinentes o importantes para la satisfacción de determinadas necesidades de una determinada población... debido a que hacen posible o facilitan el acceso para que los ciudadanos participen en la vida democrática, integren la representación nacional y accedan al poder político" (González Oropeza y Báez Silva, 2010).

La Constitución mexicana reconoce la importancia de los partidos políticos para el régimen democrático y establece un conjunto de medidas a fin de asegurar la viabilidad de estas entidades, de manera que además de salvaguardar su existencia como figuras esenciales del régi- 
men político mexicano, les otorga prerrogativas para el sostenimiento de sus actividades. El artículo 41 constitucional es el punto de inicio para un conjunto de normas reglamentarias de los partidos políticos, que incluyen los requisitos para su registro, para tener acceso a las prerrogativas y para establecer los montos de su financiamiento.

Queda la cuestión de si la regulación vigente en la Constitución y el Cofipe es suficiente para conducir la vida y actividades de los partidos políticos con certeza y congruencia con los fines para los cuales fueron creados. Es nuestro propósito aquí postular la necesidad de una regulación específica, contenida en una ley de partidos políticos.

\section{El debate sobre la regulación}

El principal escollo para justificar la regulación de los partidos políticos se encuentra en el carácter ciudadano y voluntario que estas organizaciones tienen en las democracias. A diferencia de los regímenes no democráticos, en los que la afiliación al partido oficial puede ser obligatoria, o por lo menos necesaria para evitar ser perseguido políticamente como suele suceder en regímenes de partido único (es el caso de los partidos comunistas en China, Vietnam y Cuba), en las democracias la participación ciudadana es un valor que se ejercita de manera personal y voluntaria. En lugar de un partido coludido con el Estado y auspiciado por éste, en las democracias se da una pluralidad de fuerzas partidistas provistas de libertad ideológica y de expresión, autonomía financiera y operativa, así como independencia para actuar y opinar libremente acerca de las políticas públicas y el desempeño de los gobernantes.

Las características de las que gozan los partidos en las democracias representativas propicia la equidad en la competencia electoral, así como la presencia de una oposición crítica al gobierno. Esto les brinda la posibilidad de competir de manera civilizada para reemplazar al partido en el poder y eventualmente llegar a ocupar su lugar. Para quienes confían en una legislación general, como ocurre en Estados Unidos e Inglaterra, esta independencia sería imposible si el poder público tuviera medios para vigilar y controlar las actividades partidistas. Así, una regulación menos exhaustiva del quehacer partidista es la predominante en los sistemas de partidos anglosajones, en don- 
de no cuentan con financiamiento público, ni prerrogativas estatales, pero sí gozan de garantías para el libre ejercicio de sus actividades de reclutamiento, proselitismo y competencia electoral.

El argumento de los países referidos considera a los partidos como organizaciones de ciudadanos cuya existencia es reflejo y resultado de las libertades democráticas de reunión, asociación y expresión de las ideas políticas, por lo que la intromisión estatal en su vida interna repercute en la independencia de aquéllas (Janda, 2009: 7). En el extremo opuesto se encuentran los defensores de la regulación (Janda, 2009; Zovatto, 2012) quienes la ven como un medio para salvaguardar la propia independencia de los partidos frente a intereses particulares o corporativos, con el propósito de garantizar que el objetivo primordial de estas entidades sea el interés nacional.

Así, la regulación de los partidos políticos oscila entre dos polos: una excesiva o una escasa reglamentación. El principal elemento a considerar aquí es ¿qué tanto debe el Estado inmiscuirse en la vida interna de los partidos políticos? (Zovatto, 2012: 48).

Kenneth Janda (2009: 10-21) identifica cuatro modelos de regulación de los partidos políticos: el de proscripción, el de permiso, el de promoción y el de protección. El modelo de proscripción recurre a la prohibición de ciertas prácticas o actividades, por ejemplo, la comisión de actos terroristas o la aceptación de financiamiento proveniente de fuentes ilícitas. El modelo de permiso consiste en señalar a los partidos qué actividades pueden realizar, cómo deben escoger a sus dirigentes y cómo deben financiar sus operaciones. El modelo de promoción se encuentra en las leyes que fomentan, apoyan e impulsan la creación y permanencia de los partidos políticos. Y finalmente, el modelo de protección resguarda a estas entidades contra daños y riesgos para su existencia, a través de medidas como la exclusividad (en los sistemas de partido único), el monopolio de la facultad para postular candidatos a órganos de gobierno y representación, así como la regulación de las actividades legislativas, de manera tal que en los órganos de representación se garantice la disciplina partidista.

En México, el artículo 41 constitucional incluye aspectos de permiso al establecer que los partidos son los medios por los cuales los ciudadanos podrán acceder al poder público, de protección al otorgarles un papel fundamental en la integración de la representación política y de promoción al establecer prerrogativas para el sostenimiento de sus 
actividades ordinarias y de campaña. ${ }^{2}$ La Constitución incluye además elementos de proscripción, al establecer límites para el financiamiento privado y el acceso a los medios de comunicación.

Algo similar ocurre con la ley reglamentaria en materia electoral. El libro segundo del Cofipe contiene una extensa regulación en materia de partidos que incluye los requisitos formales que deben cumplir las organizaciones de ciudadanos que aspiren a obtener el registro como partidos políticos; los contenidos mínimos que deben incorporar en sus documentos básicos; el número mínimo de afiliados distribuidos en el territorio nacional que deben acreditar; sus obligaciones en materia de transparencia; así como las reglas para el otorgamiento y distribución del financiamiento público y los espacios en radio y televisión que se les otorgan como prerrogativa.

Para Lorenzo Córdova (2011: 144) la legislación vigente en México sobre los partidos políticos es abundante y exhaustiva, lo que pudiera llevar a suponer que en estricto sentido es innecesaria una ley de partidos. Sin embargo, existen argumentos para considerar que su existencia traería consigo mejoras en varios aspectos. En tópicos tales como en los tiempos y procedimientos para el registro de nuevos partidos; en la posibilidad de que los partidos nacionales que pierden el registro pero que cuentan con suficiente presencia en algunas entidades puedan sobrevivir, como partidos locales; en las obligaciones partidistas en materia de transparencia, y en una mayor precisión regulatoria en temas como los actos anticipados de campaña, entre otros.

En el caso mexicano existe otro aspecto por el cual la regulación de los partidos políticos resulta necesaria y obligatoria. Como se mencionó antes, el artículo 41 constitucional considera a los partidos entidades de interés público y promueve su formación a través del otorgamiento de financiamiento público y prerrogativas que provienen de recursos estatales. La necesidad de contar con certeza sobre el uso y destino de esos recursos es una razón de peso para considerar mejorar la regulación de los partidos a través de una ley específica.

El libro segundo del Cofipe define los procedimientos para el cálculo del financiamiento anual que corresponde a cada partido político,

2 Sobre el aspecto de la protección hay que señalar que recientemente fue aprobada la figura de las candidaturas independientes. Por lo cual, los partidos ya no son los únicos entes que pueden postular candidatos a cargos de elección popular; sin embargo, aún está pendiente la reglamentación que permita su ejercicio. DOF, 9 de agosto de 2012. 
así como la asignación de los tiempos estatales que se le otorgan para la promoción de sus programas y plataformas políticas. ${ }^{3}$

Ciertamente, los montos otorgados a los partidos políticos son cuantiosos. No obstante, lo más importante no es el tamaño de las aportaciones sino el propósito que atienden: consolidar un sistema de partidos plural, estable e independiente de intereses ajenos o contrarios al bien común, a través de la equidad en la competencia electoral y la necesaria transparencia en el origen y aplicación de los recursos económicos de los partidos (Hernández, 2008: 43).

En efecto, los recursos que se otorgan a los partidos están vinculados al objetivo de incentivar sus actividades como entidades de interés público. Por tal motivo, el Cofipe prevé procedimientos para que sus bienes sean liquidados y reincorporados al patrimonio de la federación en caso de pérdida de su registro.

Los recursos partidistas son públicos y no dejan de serlo durante su ejercicio, de tal manera que los bienes adquiridos con éstos también se consideran públicos (Córdova y Zovatto, 2012). De ahí que la vigilancia puntual y rigurosa sobre el uso que se hace de los mismos sea una actividad ineludible, como lo es también su regulación. En otras palabras, la reglamentación de las actividades partidistas, la fiscalización de los recursos y la verificación del uso legal que se hace de ellos son acciones indispensables para salvaguardar el buen manejo del dinero y las prerrogativas que se entregan a los partidos políticos.

El diseño institucional de los partidos en México no corresponde al de organizaciones ciudadanas independientes de los recursos públicos, cuya autonomía dependa de la falta de regulación en sus asuntos internos. Se trata, por el contrario, de un sistema de pluralismo promovido y protegido desde el Estado, en donde el otorgamiento de prerrogativas y financiamiento son elementos centrales para garantizar dos elementos estratégicos:

- La formación de una escena de competencia y competitividad electorales y

3 En 2012, el monto para el sostenimiento de actividades ordinarias de los partidos políticos fue de \$3361 120841.57 , a los que se sumaron \$67222416.83 destinados a la capacitación, promoción y el desarrollo del liderazgo político de las mujeres; $\$ 134444833.66$ para franquicias postales para el ejercicio, además de $\$ 693497.00$ para franquicias telegráficas y $\$ 1680560420.78$ para actos de campaña correspondientes a las elecciones de presidente de la República, senadores y diputados. IFE: CG431/2011, pp. 15-19. 
- La lealtad de los propios partidos hacia el régimen, de tal manera que no se desvíen a actividades contrarias a la democracia.

Asimismo, el régimen de prerrogativas vigente resulta crucial para evitar que, en la búsqueda de recursos para su sostenimiento, los partidos y la clase política afiliada a ellos, establezcan compromisos con grupos económicos, delictivos o de cualquier otro tipo que pudieran desviar los propósitos de la actividad partidista.

El modelo de financiamiento de los partidos en México trata de evitar que éstos se desvíen hacia intereses ajenos a la democracia y la representación popular. El financiamiento estatal va de la mano de la fiscalización, con la finalidad de evitar que el dinero público destinado a los partidos se use para otros propósitos.

El financiamiento público a los partidos políticos es un motivo suficiente para demandarles un comportamiento apegado a los valores democráticos interna y externamente. En este sentido, el establecimiento de una ley de partidos resulta un marco ideal para obligarlos a modificar su comportamiento, el cual hasta el momento provoca, por lo menos, un gran desencanto ciudadano hacia la política.

Hay más razones que justifican la regulación y apuntan hacia la pertinencia de dar más claridad al sistema normativo vigente. Daniel Zovatto (2011: 45) considera la necesidad de regular como un remedio indispensable para esclarecer las normas para la formación, organización, financiamiento, facultades, límites, derechos y deberes de los partidos políticos, lo mismo que su estructura y principios de organización. Para Zovatto, con ello se atendería la crisis de credibilidad que aqueja a los partidos políticos mediante el fortalecimiento de su democracia interna, además de garantizar el cumplimiento de sus obligaciones en materia de transparencia y rendición de cuentas. La falta de definición actual en estas materias ha dado lugar, con cierta frecuencia, a que los partidos ignoren los principios democráticos y se guíen por el interés privado.

González Oropeza y Báez Silva (2010) llaman la atención sobre la judicialización de los asuntos de los partidos políticos como una consecuencia de la intención de salvaguardar sus objetivos consagrados en el artículo 41 constitucional. Esto, a través del ejercicio de las facultades jurisdiccionales que tratan de esclarecer aquello en lo que las normas no son suficientemente nítidas, pero terminan por sustituir la legislación. El resultado es que los militantes de tales organizaciones 
acuden a la autoridad jurisdiccional en materia electoral para resolver las controversias que los partidos no pueden solucionar en su interior por carecer de normas claras y árbitros imparciales. En consecuencia, el Tribunal Electoral del Poder Judicial de la Federación (TEPJF) y los tribunales electorales de las entidades federativas se ven en la necesidad de resolver asuntos que deberían ser solventados en el interior de los propios partidos.

Tanto Zovatto como Córdova apuntan que no se trata sólo de tener una regulación en materia de partidos, sino de la urgencia de que ésta sea clara, precisa y sistemática. En la actualidad, la legislación sobre partidos vigente en México se encuentra contenida tanto en la Constitución como en el Cofipe, además de diversos reglamentos y acuerdos aprobados por el Instituto Federal Electoral (IFE), con el propósito de esclarecer aspectos tan específicos como los procedimientos para verificar el cumplimiento de requisitos para la obtención del registro, o los procedimientos administrativos y contables que se siguen para llevar a cabo la fiscalización de los recursos partidistas. Al marco regulatorio hay que agregar también las tesis de jurisprudencia y sentencias emitidas por las autoridades jurisdiccionales con el objetivo de dar certeza en aspectos como la democracia interna de los partidos políticos.

Concentrar en un solo documento legal las disposiciones actualmente diseminadas, en una ley de partidos, permitiría hacer la regulación más funcional, al tiempo que permitiría armonizarla y evitar los espacios de opacidad que pudieran fortalecer intereses contrarios a la democracia.

\section{Contenidos mínimos de una ley reglamentaria}

Hasta aquí hemos visto que tener una ley de partidos sería de utilidad para contar con una regulación más clara y consistente de esas organizaciones, sus actividades y el uso que hacen de los recursos públicos que se les otorgan; quedan ahora por esclarecer los temas que debería incluir esa regulación.

Para Daniel Zovatto (2006) existen dos cuestiones relevantes relacionadas con la regulación de los partidos. La primera, se refiere a los límites que el Estado debe observar con respecto a su regulación 
jurídica, respetando al mismo tiempo la libertad de actuación de los partidos. La segunda, consiste en la necesidad de que haya coherencia entre los principios democráticos, ya plasmados en la Constitución, y los valores y reglas internas de los partidos. Zovatto observa que las legislaciones partidistas vigentes en los países del subcontinente coinciden en regular la naturaleza jurídica de los partidos, sus funciones, las reglas para formarlos o registrarlos, y la democracia interna de los mismos; sin embargo, también muestra que la regulación de los partidos suele incluir temáticas como los sistemas de financiamiento y el acceso a los medios de comunicación, las cuotas de género, los requisitos para formar coaliciones, las condiciones para su extinción y el transfuguismo político, cuestiones que también podrían ser incorporadas en una ley mexicana.

Por su parte, José Dávila (2006) desarrolla un listado más exhaustivo de los contenidos que podría incluir una ley que busque promover la consolidación partidaria al tiempo que la coincidencia de las ideologías de los partidos con los valores y fines de la democracia. Su propuesta incluye la democratización interna; la promoción de políticas de género; capacitación y formación de sus cuadros y militantes; simplificación de los programas de reclutamiento partidario; reglamentación del trabajo permanente con las bases; fortalecimiento del perfil ético de los partidos con un sentido de servicio social; socialización de los puestos y cargos públicos; esto es, desconcentrar los privilegios de las élites dentro de los partidos, además del reforzamiento de los lazos de comunicación y cooperación con otras organizaciones.

Más moderada es la posición de Richard Kats (1995) quien identifica tres objetivos que deben seguir las leyes que regulan a los partidos políticos: determinar qué es un partido político, regular el tipo de actividad en la cual pueden involucrarse los partidos políticos y asegurar formas apropiadas de organización y comportamiento partidista.

Córdova (2011) considera de gran importancia reglamentar los requisitos para obtener el registro partidista, las obligaciones en materia de fiscalización y transparencia, y lo relativo a sus actividades de precampaña y campaña electoral.

Más allá de posturas minimalistas o maximalistas, los autores citados coinciden en la necesidad de regular el estatus jurídico de los partidos; los requisitos para la obtención del registro; las reglas y procedimientos para determinar y distribuir el financiamiento público 
y las prerrogativas en radio y televisión; la transparencia partidista, los procesos de democracia interna; las reglas y responsabilidades del partido relacionadas con la competencia electoral; las reglas para la equidad de género en el interior de estas organizaciones; además de los procedimientos relativos a su extinción y la liquidación de sus bienes.

Córdova (2011: 137) considera que en México los partidos políticos tienen un estatus mixto, como entes públicos y privados simultáneamente. Este carácter de figuras públicas, unido al conjunto de prerrogativas y recursos que reciben del Estado, se traduce en una obligación de los partidos frente a la sociedad de rendir cuentas sobre el uso y destino de esos recursos. También tienen el carácter privado ya que son organizaciones que poseen principios, fines e ideologías propias. En este sentido son independientes del Estado pero funcionales al régimen democrático.

Una ley de partidos en México permitiría definir con claridad el alcance que se desea dar a la intervención de la autoridad electoral en su vida interna; esto es, si se limitará a verificar la legalidad de los procedimientos y mecanismos que los partidos determinen para elegir a sus órganos directivos y candidatos, así como la resolución de sus controversias internas; si se podrán establecer lineamientos sobre las características de la normativa interna de los partidos; si los procedimientos internos estarán sujetos a alguna verificación por parte del órgano electoral; si las autoridades podrán o no resolver controversias, entre otros temas.

En cualquier caso, hay un conjunto de aspectos mínimos que una ley de partidos en México debiera incluir. Algunos de ellos, como las reglas y requisitos para obtener y conservar el registro ya están considerados, mientras que otros, como las responsabilidades de candidatos, funcionarios partidistas, militantes y simpatizantes en caso de infringir las reglas relativas al acceso a radio y televisión, actualmente están contemplados en el Cofipe, pero son omisos en cuanto a esclarecer si la responsabilidad por actos y conductas sancionables en materia de fiscalización puede alcanzar, o no, a los candidatos.

A continuación se presentan algunos de los temas que deberían ser incluídos en una iniciativa de ley de partidos que tenga como propósito fortalecer la competencia electoral equitativa y plural en nuestro país. 


\section{Regulación de las reglas y requisitos para obtener y conservar el registro}

Los obstáculos para obtener el registro como partido político en México tienen su origen en la ley electoral de 1946. Antes de ella, la reglamentación no era muy detallada al respecto. En la ley de 1916 sólo se señalaba como limitante el no ostentar una denominación con connotación religiosa, ni constituirse para favorecer una determinada raza o creencia. Mientras que la de 1918 señalaba que un partido político se fundaría por medio de una asamblea constitutiva con por lo menos cien miembros. Por su parte, la ley de 1946 establecía: a) contar con treinta mil asociados en el país, diseminados, cuando menos, en dos terceras partes de las entidades federativas, que se organizarían con mil afiliados como mínimo; b) obligarse a actuar de acuerdo con los preceptos de la Constitución; c) la consignación en su acta constitutiva de no subordinarse a una organización internacional; $d$ ) que establecieran mecanismos de elección interna para la designación de sus candidatos (Rodríguez y Sirvent, 2005: 189).

En adelante, las sucesivas leyes electorales señalaban condiciones muy similares: formales, numéricas y territoriales. Las primeras referentes a documentos básicos; las segundas, relacionadas con el requisito de contar con un número determinado de afiliados en todo el país, $\mathrm{y}$ las últimas, con la presencia y participación de las asambleas regionales de constitución del partido en estados o distritos (Córdova, 2012: 148). Actualmente estas exigencias permanecen como requisitos para el otorgamiento del registro a nuevos partidos.

En el Cofipe se establecen los siguientes requisitos: declaración de principios, programa de acción y estatutos, tener un número total de afiliados equivalente al $0.26 \%$ del padrón electoral y contar con la presencia y participación de las asambleas regionales de constitución del partido de 3000 afiliados en 20 entidades o bien de 300 afiliados en 200 distritos electorales, al menos (Cofipe, título II, capítulo I). La solicitud de registro para un nuevo partido político nacional, desde la reforma electoral de 2007-2008, quedó establecida para enero del año posterior a la elección presidencial.

Para contrarrestar las exigencias anteriores, se debería tener presente en una posible ley de partidos, la pertinencia de asegurar el derecho constitucional a la asociación política y, por ello, se tendrían que flexibilizar los requisitos para el registro de nuevos partidos. 
En este sentido, sería viable reintroducir el sistema de registro condicionado que se estableció en 1977 con la reforma política de ese año, para permitir que el electorado dé el veredicto sobre la eventual permanencia de los partidos. En esa tesitura, siguiendo con el derecho de asociación, sería muy positivo alentar la reactivación de los partidos locales y no sólo de los nacionales, estableciendo una serie de reglas complementarias, tales como un umbral más alto para acceder al financiamiento público (Reveles, 2008b: 77).

\section{Regulación de los procedimientos y responsabilidades en caso de pérdida del registro}

Además de la puerta de entrada, también es necesario considerar la de salida de la liza electoral. La falta de un adecuado esquema legal que dé prioridad a la libertad de organización política conduce a que las expresiones políticas que no logren cumplir con los requisitos sean eliminadas. Ello nos deja ver que a pesar de tener arraigo en ciertas zonas, incluso de ganar curules, no hay garantía de que un partido político permanezca, lo cual limita la pluralidad política.

Entre los elementos que conducen a la eliminación de un partido político se encuentran los siguientes: a) no participar en el proceso federal ordinario; b) no obtener en la elección federal ordinaria inmediata anterior, por lo menos el $2 \%$ de la votación; c) haber dejado de cumplir con los requisitos necesarios para obtener el registro; d) incumplir las obligaciones que señala el Cofipe; $e$ ) haber sido declarado disuelto por acuerdo de sus miembros conforme sus estatutos, y f) haberse fusionado con otro partido político (Cofipe, artículo 66).

Antes de la reforma de 2007-2008 no se tenía contemplado el procedimiento a seguir en caso de pérdida del registro de los partidos políticos, ni tampoco en lo referente al destino de sus recursos materiales. La nueva norma estableció que los recursos y bienes remanentes de los institutos políticos sean adjudicados a la federación. Además, la Unidad de Fiscalización de los Partidos Políticos del IFE se encargará de designar a un interventor responsable del control directo del uso y destino de los recursos y bienes del partido que se trate (Constitución, artículos 41, Base II; 116, Base IV, g, y Cofipe, artículo 103.1, a y b).

Resulta relevante tener presente que en el periodo que va de 1991 a 2010 han perdido el registro 19 partidos políticos nacionales (anexo 1). El principal motivo fue no obtener el mínimo de votación requeri- 
da (2\%). En muy pocos casos estos partidos han podido transformarse en partidos locales y, por ello, la representación que llegaron a tener se perdió. Una posible ley de partidos permitiría valorar el hecho de que un factor que explica la crisis de representación pudiera ser la existencia de pocas alternativas políticas.

Asimismo, dado que el financiamiento público a los partidos depende de la obtención del registro, éste constituye un elemento que favorece las opciones políticas de alcance nacional y con una organización sólida que difícilmente se logra a nivel subnacional.

De tal manera, la flexibilización de las normas para obtener el registro nacional, y el desarrollo de un sistema de partidos local parecen ser temas que revitalizarían el exiguo modelo vigente.

\section{Establecimiento de una regulación coherente y unificada relativa a prerrogativas y financiamiento}

El financiamiento a los partidos es un tema sobre el que se han expresado críticas y puntos de vista encontrados. El modelo mexicano ha establecido un sistema mixto, en el que el financiamiento público coexiste con el privado, aunque desde la reforma de 1996 se estableció que el público primara sobre cualquier otro. Además, se otorgaron grandes cantidades de dinero a los partidos políticos para evitar de ellos un comportamiento inapropiado en la búsqueda de ganar elecciones.

La reforma de 2007-2008 modificó la fórmula para asignar el financiamiento a los partidos. Actualmente el monto se establece a partir de la aplicación de una fórmula según la cual se multiplica el número total de ciudadanos inscritos en el padrón electoral, por el $65 \%$ del salario mínimo diario vigente para el Distrito Federal. El 70\% del financiamiento ordinario se distribuirá considerando la votación nacional emitida en la elección de diputados de mayoría relativa, inmediata anterior, y el 30\% restante se distribuirá en forma igualitaria entre los partidos políticos con representación en el Congreso de la Unión.

Para las actividades de campaña se estableció que cada partido recibiría un monto equivalente al $50 \%$ del financiamiento público ordinario en año de elección presidencial y al 30\% cuando sólo se renueve la Cámara de Diputados. El financiamiento público siguió prevaleciendo sobre el privado. Dentro del primer tipo se incluyeron: actividades 
permanentes, de campaña y específicas. En el financiamiento privado las modalidades son: rendimientos financieros, autofinanciamiento, de simpatizantes y de militantes (Constitución, artículo 41, y Cofipe, artículo 78).

Aunque en la reforma de 2007-2008 se menciona que los partidos que hubieren obtenido su registro con fecha posterior a la última elección y aquellos que, conservando el registro, no tuvieran representación en el Congreso, tendrán derecho a recibir el $2 \%$ del monto que por financiamiento total les corresponda para el sostenimiento de sus actividades ordinarias permanentes, sólo en lo que corresponde al 30\% que se distribuye de forma igualitaria (Cofipe, artículo 78). De nuevo, se constata aquí el hecho de hacer depender el financiamiento público a los partidos de la obtención del registro es un elemento que favorece a los que cuentan con una estructura nacional y han competido en elecciones previas.

Por otra parte, no se debe perder de vista que la seguridad que se da a los partidos a través del financiamiento público ha tenido también consecuencias inesperadas en la medida en que se han distanciado de la sociedad y la militancia. Si se condicionara el monto del financiamiento a un porcentaje de la votación, la relación probablemente cambiaría, ya que a fin de garantizar sus ministraciones, los partidos buscarían a la ciudadanía de manera constante y no únicamente en los periodos electorales. En suma, el financiamiento mixto parece ser el adecuado, aunque se debe fortalecer la transparencia y fiscalización de los recursos destinados a los partidos. El fondo del asunto es el gasto responsable de los recursos públicos, así como la equidad en la competencia.

\section{Definición de los alcances de la autoridad en la vigilancia de los actos partidistas}

Manuel González Oropeza y Carlos Báez Silva (2010: 59) contabilizan más de ocho mil juicios para la defensa de los derechos políticoelectorales de los ciudadanos ante el TEPJF, entre 2003 y 2009; 53\% de ellos referentes a controversias internas de los partidos políticos. En opinión de estos autores, la cantidad de asuntos intrapartidistas que llegaron, como última instancia de resolución, al conocimiento del Tribunal Electoral da cuenta de la confianza que los ciudadanos 
depositan en este órgano jurisdiccional. Sin embargo, también es una muestra de la cantidad de asuntos que los partidos no consiguen procesar y resolver internamente.

De acuerdo con González Oropeza y Báez, la jurisprudencia emitida por la Sala Superior del Tribunal apunta hacia un conjunto de características que debería tener la normativa interna de los partidos. Por ejemplo, contar con procedimientos claros y consensuados para la elección de las dirigencias, establecer una periodicidad amplia para la duración en los cargos de dirección partidista, así como la inclusión de procedimientos intrapartidistas que sean compatibles con las garantías de equidad y certeza establecidas en la Constitución para la solución de controversias, entre las principales.

Esto se traduce en la necesidad de regular con precisión los elementos mínimos que deberían contener los documentos normativos partidistas en aspectos como la denominación, integración y atribuciones de sus órganos directivos; procedimientos para seleccionar a los integrantes de dichos órganos y duración en el cargo, además de establecer la existencia de instancias internas para la solución de controversias cuyos procedimientos y reglas sean congruentes con la equidad, imparcialidad, objetividad, certeza y transparencia que la Constitución establece para las instituciones encargadas de resolver quejas y arbitrar controversias. De tal manera, una ley electoral también habría de regular y definir los procedimientos de queja, denuncia, disciplinarios internos y sanciones aplicables.

\section{Definición de las responsabilidades de candidatos, funcionarios partidistas, militantes y simpatizantes}

El libro séptimo del Cofipe, actualmente en vigor, que regula los regímenes sancionador electoral y disciplinario interno, precisa qué sujetos están obligados a cumplir la ley electoral y qué responsabilidades y sanciones se les pueden adjudicar en caso de infringirla.

Sin embargo, aún es necesario esclarecer si los partidos políticos se pueden considerar responsables de las infracciones que cometan sus candidatos, militantes y simpatizantes. De tal manera, es imperativo contar con criterios que distingan los alcances de la responsabilidad de un partido o, para decirlo de manera llana, hasta dónde comparte 
una organización partidista la responsabilidad de las conductas indebidas de sus simpatizantes o de los seguidores de sus candidatos.

El mismo esclarecimiento de la responsabilidad se puede señalar en sentido opuesto; es decir, definir si un candidato puede ser sancionado por conductas indebidas atribuibles a los órganos o dirigentes del partido político que lo postula, en asuntos como el rebase de topes de campaña. En consecuencia, se podría determinar si un candidato es responsable por infracciones que él no cometió de manera directa y de las cuales puede alegar no tener conocimiento a pesar de que real o potencialmente le hayan beneficiado.

Criterios similares podrían aplicarse para determinar si se considerarían responsables a los partidos y candidatos por conductas inapropiadas que cometan sus simpatizantes por iniciativa propia, tales como agredir físicamente a los simpatizantes o candidatos de otro partido, retirar la propaganda de sus oponentes o intimidar a los votantes potenciales. El propósito de estas definiciones no se limitaría a establecer los alcances de las sanciones, sino también, y sobre todo, a promover la vigilancia de los partidos sobre las acciones de sus simpatizantes, militantes y candidatos.

Por otra parte, al hacer a los candidatos responsables y solidarios de las infracciones cometidas por los órganos de su partido, se estimularía una actitud más responsable e informada por parte de estos últimos y, probablemente, una comunicación más constante y directa entre candidatos, partidos y dirigencias. Una consecuencia adicional, sería la promoción de regulaciones claras y precisas en el interior de los partidos políticos en temas como financiamiento privado, actos de precampaña y campaña y actos proselitistas anticipados a los tiempos establecidos por la legislación electoral. Los partidos verían la necesidad de armonizar sus normas internas con la legislación en materia de partidos y elecciones a fin de procurar, desde su interior, cumplir con las leyes y evitar sanciones.

Así, la ley de partidos podría establecer los criterios generales que adoptarían éstos para la generación de reglas internas compatibles con las leyes electorales y los principios democráticos consagrados en la Constitución. Mejor aún, al establecer tales lineamientos, sería innecesario que la ley de partidos regulara aspectos demasiado específicos de la vida partidista, que los propios partidos deben procesar y aprobar libremente en su interior. 
6. Determinación de los procedimientos de queja, denuncia, disciplinarios internos y sanciones aplicables

Ante la falta de legislación sobre el tema, actualmente la vida interna de los partidos políticos en México mantiene una jerarquía muy marcada en cuanto a los derechos de los líderes sobre los de los militantes. Se trata de un arreglo tácito en el que las bases no tienen los medios suficientes para hacer valer sus derechos dentro de la organización.

Al respecto, para Reveles (2008b: 40) resulta significativo que desde la creación del Tribunal Electoral (actualmente Tribunal Electoral del Poder Judicial de la Federación) se haya dado lugar a un gran número de denuncias presentadas por los militantes ante las autoridades encargadas de impartir justicia en materia electoral. Además de ello, resalta el hecho de que generalmente se les dio la razón a los militantes, en detrimento de los dirigentes.

Una ley de partidos, debería de buscar introducir mecanismos de justicia al interior de los partidos, fundamentalmente para asegurar los derechos de los militantes. Reveles (2008b: 75) propone una defensoría del militante (autónoma de los líderes) que se encargue de hacer respetar el derecho de los miembros, así como también el de los líderes en procesos de revocación del mandato.

El derecho más visible y que usualmente los militantes ven coartado es el de contender para una candidatura interna o externa. Aunque de manera más general se puede mencionar el derecho de participar en la toma de decisiones de la organización, que la mayoría de las veces se reduce a elecciones internas exclusivamente.

\section{Regulación de los actos partidistas para obtener financiamiento privado}

De acuerdo con el régimen de financiamiento, los partidos tienen la posibilidad de recolectar por sus medios hasta un $10 \%$ del monto establecido como tope de gasto de campaña para la elección presidencial anterior. El financiamiento que no proviene del erario tiene origen privado, que se puede obtener por rendimientos financieros, y por autofinanciamiento, de simpatizantes y de militantes (CPEUM, artículo 41, y Cofipe, artículo 78). 
En términos generales, la preponderancia del dinero público exime en alto grado la obligación de los ciudadanos para sostener mediante cuotas a los partidos. El partido de masas, de acuerdo con Duverger, se sostenía primordialmente por las cuotas de los militantes quienes tenían un compromiso ideológico profundo con su organización. Aquel modelo se reemplazó por el financiamiento mixto.

Los riesgos del financiamiento exclusivamente privado son muy grandes pues las fuentes ilícitas son latentes; pero los recursos públicos no incentivan el acercamiento de los partidos con la sociedad con el objetivo de atender a sus demandas, sino que contribuyen al desapego de la militancia.

El modelo de financiamiento mixto que prevalece en México ha dado muestra de su conveniencia. Sin embargo, los partidos deben acercarse a su militancia, aunque lamentablemente el hecho de tener una fuente de recursos estable ha relajado esta cohesión e identidad partidista. Esta identidad debe fortalecerse a través de la obligación de los partidos de organizar actos públicos, especialmente con sus bases, mediante los cuales pudieran hacerse de recursos.

\section{Conclusiones}

La regulación partidista contenida en la Constitución permite que los partidos existan como puentes entre la ciudadanía y el poder público, los protege al darles la primacía de la integración de la representación popular y promueve su existencia a través del financiamiento y el otorgamiento de prerrogativas, pero también proscribe que los recursos otorgados a estas entidades sean utilizados para fines distintos a los señalados por el propio artículo 41 de la carta magna.

Pese a que la mayoría de los estudios referentes a la posible creación de una ley de partidos en México muestran su pertinencia y viabilidad, existe una dificultad por sortear en el hecho de que serían los propios partidos políticos quienes, a través de sus legisladores, aprobarían una norma que establezca más control y vigilancia para sus institutos políticos.

En efecto, el desafío para conseguir la aprobación de una ley de este tipo está sujeto a que los partidos, representados en el Congreso, estén convencidos de su pertinencia y necesidad. Difícilmente estas organi- 
zaciones aprobarían una ley que limitara sus privilegios o aumentara la carga de sus responsabilidades. El convencimiento para discutir y aprobar una ley de partidos deberá arrancar, inevitablemente, de la convicción de que a los partidos políticos, junto con sus dirigentes y militantes, les beneficia contar con un marco normativo que proteja su estatus jurídico y sus prerrogativas.

Por otra parte, no se puede soslayar el riesgo de caer en una sobrerregulación o, más grave aún, en conseguir lo contrario de lo que se pretende obtener. No se lograría un sistema de partidos más sólido, confiable, transparente y comprometido con los ciudadanos, sino un conjunto de organizaciones partidistas agobiadas por una reglamentación excesiva, más burocratizadas y desligadas de la sociedad.

Con todo, la regulación de los partidos políticos es indispensable en un sistema partidista como el mexicano, que los considera entidades de interés público y los beneficia con recursos oficiales. Ante esta realidad resulta innecesario preguntar qué tanto puede el Estado inmiscuirse en la vida interna de los partidos políticos, toda vez que estas organizaciones son, de hecho, parte del mismo.

Además, una ley de partidos podría introducir incentivos para que los partidos se acerquen a la ciudadanía, para que los militantes encuentren sus derechos fortalecidos frente a las élites partidistas y para motivar a los propios partidos a revisar sus normas internas y hacerlas más congruentes con lo que se espera de ellos. Y esto último es que actúen como entidades de interés público encargadas de formar opinión y representación nacional.

Es cierto que no se puede plantear la regulación de los partidos como la panacea; después de todo, los partidos mexicanos ya están sujetos a una regulación relativamente amplia, pero es posible esperar resultados favorables de una reforma legal que tenga claros sus propósitos. La necesidad es concentrar en una sola ley un conjunto de disposiciones que hoy se encuentran dispersas en varios textos legales pero, ante todo, dar claridad respecto de los actos, decisiones y responsabilidades de estas entidades que operan y prosperan con recursos del erario. En última instancia, un adecuado diseño legal para los partidos mexicanos no solamente arrojaría más certidumbre y transparencia sobre sus actos, pues podría incentivar el retorno de los partidos a los principios que les dieron origen. Sólo así podrían dejar de ser vistos como pasivos de la democracia para transformarse en organizaciones comprometidas con la sociedad, el bien común y el ejercicio ético de la política. 
Una ley de partidos no solamente mejoraría la vigilancia ciudadana e institucional sobre ellos, también daría certeza a estas organizaciones, a sus dirigentes y militantes acerca de sus derechos, obligaciones y responsabilidades.

En la protección de los derechos y privilegios que los partidos tienen como entidades de interés público, está la dificultad para aprobar una iniciativa en la materia. Concretamente, la regulación partidista crearía incentivos para que los partidos cumplan con los fines democráticos para los que, conforme a la Constitución, fueron creados. Cumplir con esos fines y propósitos es lo que requieren los partidos para recuperar la confianza de la ciudadanía.

\section{Bibliografía}

Abal Medina, Juan, 2002, “Elementos teóricos para el análisis contemporáneo de los partidos políticos: un reordenamiento del cambo semántico", en Cavarozzi, Marcelo y Abal Medina, Juan (eds.), El asedio a la política. Los partidos latinoamericanos tras la década del neoliberalismo, Rosario, Homo Sapiens.

Alcántara Sáez, Manuel, 2001, El origen de los partidos políticos en América Latina, Barcelona, Institut de Ciències Polítiques i Socials Working Paper núm. 187, Universidad de Salamanca, disponible en http://www.recercat.net/bitstream/handle/2072/1278/ICPS187.pd $f$ ? sequence $=1$.

Calame, Pierre, 2006, La ingeniería institucional: la concepción y el funcionamiento de las instituciones. Tesis para repensar la gobernan$z a$, París, Instituto de Investigación y Debate sobre la Gobernanza, creado por iniciativa de la Fundación Charles Léopold Mayer, disponible en http://www.institut-gouvernance.org/es/analyse/ficheanalyse-325.html.

Córdova Vianello, Lorenzo, 2011, Hacia una ley de partidos políticos. Ejes temáticos para la discusión, Instituto de Investigaciones jurídicas-UNAM, disponible en http://biblio.juridicas.unam.mx/libros/7/3168/8.pdf.

Cordova Vianello, Lorenzo y Zovatto, Daniel (coords.), 2012, ¿Hacia una ley de partidos políticos? Experiencias latinoamericanas y prospectiva para México, México, UNAM-IDEA Internacional- 
Fundación Belisario Domínguez del Instituto de Investigaciones Legislativas del Senado de la República.

Crespo, José Antonio, 1991, "La evolución de los partidos políticos en México”, Foro Internacional, vol. 31, núm. 4 (124), abril-junio de 1991, disponible en http://codex.colmex.mx:899a/exlibris/alepha1 8_1/apache_media/P2VBA3H5GJRDILMGELRKX7HS271AUV.pdf. DÁvila, José, 2006, "Renovación de los partidos políticos de Centroamérica”, Diálogo Político, Alemania, Fundación Konrad-AdenauerStiftung A. C., disponible en http://www.kas.de/wf/doc/kas_99291522-1-30.pdf?080507171015.

Duverger, Maurice, 1976, Los partidos politicos, México, Fondo de Cultura Económica.

González Oropeza, Manuel y Báez Silva, Carlos, 2010, La intervención de los órganos electorales del Estado en la vida interna de los partidos políticos, México, UNAM, Instituto de Investigaciones Jurídicas.

Iniciativa social para la democracia, 2010, Regulación jurídica de los partidos políticos en Latinoamérica. Un análisis de derecho comparado. Disponible en http://www.isd.org.sv/dev/wp-content/ uploads/2010/11/AN\%C3\%81LISIS-DE-LEYES-DE-PARTIDOSPOL\%C3\%8DTICOS.pdf.

JANDA, Kenneth, 2009, Partidos políticos y democracia en perspectivas teóricas y prácticas. Adopción de una ley de partidos, Washington, Instituto Nacional Demócrata para Asuntos Internacionales, disponible en http://www.redpartidos.org/files/Adopcion_de_una_Ley_ de_Partidos_-_Kenneth_Janda.pdf.

Hernández Reyez, Angélica, 2008, Ley de Partidos Políticos, México, Serie Amarilla temas Políticos y Sociales, Cámara de Diputados-Comité del Centro de Estudios de Derecho e Investigaciones, legislativas.

Kats, Richard y MaIr, Peter 1995, How parties organize: Change and Adaptation in Party Organizations in Western Democracies, Sage publications.

La Palombara, J. y Weiner, M. (comps.), 1969, Political Parties and Political Development, Princeton, Princeton University Press.

Moya Delgado, Octaviano, s. f., Leyes de partidos en México: retos y perspectivas, Revista del Instituto de Investigaciones Legislativas del Senado de la República, disponible en http://pdba.georgetown.edu/ Parties/Mexico/Leyes/LeyPartidos.pdf. 
Negretto, Gabriel, 2008, "Paradojas de la reforma constitucional en América Latina", Journal of Democracy en español, Colombia, disponible en $h t t p: / / w w w . j o u r n a l o f d e m o c r a c y e n e s p a n o l . c l / p d f / n e g r e t t$ o.pdf.

Nohlen, Dieter, 1992, Sistemas electorales y gobernabilidad, Barcelona Universitat Heidelberg Working Paper, núm. 63, disponible en http://www.uimunicipalistas.org/xcongreso/documentacion/documentos/VI/8.pdf.

- - , 1994, Sistemas electorales y partidos políticos, UNAM-FCE.

TANAKa, Martín, 2009, ¿En qué falló la ley de partidos y qué debe hacerse al respecto? (documento de trabajo) Instituto de estudios peruanos-IDEA Internacional, disponible en http://es.scribd.com/ doc/34915175/\%C2\%BFEn-que-fallo-la-Ley-de-Partidos-Tanaka.

Reveles, Francisco, 2008a, Partidos políticos en México. Apuntes teóricos, México, Gernika.

-_- 2008b, La democracia en los partidos políticos. Premisas, contenidos y posibilidades, México, IEEM.

Rodríguez Araujo, Octavio y Sirvent Gutiérrez, Carlos, 2005, Instituciones y procesos electorales en México, México, Jorale Editores.

Pizarro Leongómez, Eduardo, 2002, La atomización partidista en Colombia: el fenómeno de las micro-empresas electorales, The Hellen Kellog Institute for International Studies Working Paper núm. 292 enero de 2002, disponible en http://kellogg.nd.edu/publications/wor kingpapers/WPS/292.pdf.

Sartori, Giovanni, 1993, ¿Qué es la democracia?, México, Patria-Tribunal Federal Electoral-Instituto Federal Electoral, disponible en http://biblio.juridicas.unam.mx/libros/libro.htm?l=1135.

_-_, 1999, "La ingeniería institucional y sus límites", Teoría y realidad constitucional, núm. 3, disponible en http://www.juridicas.un am.mx/publica/librev/rev/trcons/cont/3/est/est5.pdf.

_-_, 2005, Partidos y sistemas de partidos: marco para un análisis, Madrid, Alianza Editorial.

VALDÉs, Leonardo, 2001, Sistemas electorales y de partidos, 4a. ed., México, Instituto Federal Electoral.

Ware, Alan, 1996, Partidos políticos y sistemas de partidos, España, Itsmo.

Weber, Max, 1994, Economía y sociedad, México, Fondo de Cultura Económica. 
Zovatto, Daniel, 2006, "Regulación de los partidos políticos en América Latina”, Diálogo Político, Alemania, Fundación Konrad-Adenauer-Stiftung, disponible en $h t t p: / / w w w . k a s . d e / w f / d o c / k a s \_9929-15$ 22-1-30.pdf?080507171015.

- - - (coord.), 2011, "La regulación jurídica de los partidos políticos en América Latina”, en ¿Hacia una ley de partidos polítcos? Experiencias latinoamericanas y prospectiva para México, México, UNAM-IDEA Internacional-Instituto Belisario Domínguez del Senado de la República, disponible en http://biblio.juridicas.unam. $m x /$ libros/7/3168/5.pdf. 
Partidos políticos nacionales que han perdido su registro en el periodo 1991-2010

\begin{tabular}{|c|c|c|c|}
\hline $\begin{array}{l}\text { Partido Político } \\
\text { Nacional }\end{array}$ & $\begin{array}{l}\text { Fecha de } \\
\text { obtención de } \\
\text { registro }\end{array}$ & $\begin{array}{l}\text { Junta General } \\
\text { Ejecutiva (fecha } \\
\text { de sesión en la } \\
\text { que se declaró } \\
\text { la pérdida de } \\
\text { registro) }\end{array}$ & Motivo \\
\hline $\begin{array}{c}\text { Partido Demócrata } \\
\text { Mexicano }\end{array}$ & $\begin{array}{c}4 \text { de mayo de } \\
1990\end{array}$ & $\begin{array}{c}6 \text { de noviembre de } \\
1991\end{array}$ & $\begin{array}{l}\text { Obtuvo el } 1.03 \% \text { de la } \\
\text { votación emitida en la } \\
\text { elección de Diputados por } \\
\text { ambos principios y el } 1.16 \% \\
\text { en la de Senadores. }\end{array}$ \\
\hline $\begin{array}{c}\text { Partido } \\
\text { Revolucionario de } \\
\text { los Trabajadores }\end{array}$ & $\begin{array}{c}22 \text { de enero } \\
\text { de } 1991 \\
\text { (condicionado) }\end{array}$ & $\begin{array}{c}6 \text { de noviembre de } \\
1991\end{array}$ & $\begin{array}{c}\text { Obtuvo el } 0.56 \% \text { de la } \\
\text { votación emitida en la } \\
\text { elección de Diputados por } \\
\text { ambos principios y el } 0.64 \% \\
\text { en la de Senadores }\end{array}$ \\
\hline Partido del Trabajo & $\begin{array}{c}22 \text { de enero } \\
\text { de } 1991 \\
\text { (condicionado) }\end{array}$ & $\begin{array}{c}6 \text { de noviembre de } \\
1991\end{array}$ & $\begin{array}{l}\text { Obtuvo el } 1.07 \% \text { de la } \\
\text { votación emitida en la } \\
\text { elección de Diputados por } \\
\text { ambos principios y el } 1.06 \% \\
\text { en la elección de Senadores }\end{array}$ \\
\hline $\begin{array}{l}\text { Partido Ecologista } \\
\text { de México }\end{array}$ & $\begin{array}{c}28 \text { de febrero } \\
\text { de } 1991 \\
\text { (condicionado) }\end{array}$ & $\begin{array}{c}6 \text { de noviembre de } \\
1991\end{array}$ & $\begin{array}{c}\text { Obtuvo el } 1.37 \% \text { de la } \\
\text { votación emitida en la } \\
\text { elección de Diputados por } \\
\text { ambos principios y el } 1.34 \% \\
\text { en la elección de Senadores }\end{array}$ \\
\hline $\begin{array}{l}\text { Partido Popular } \\
\text { Socialista }\end{array}$ & & $\begin{array}{l}12 \text { de diciembre } \\
\text { de } 1994\end{array}$ & $\begin{array}{c}\text { Obtuvo el } 0.47 \% \text { de la } \\
\text { votación emitida en la } \\
\text { elección Presidencial, el } 0.61 \\
\text { en la de Senadores y el } 0.67 \\
\% \text { en la de Diputados de } \\
\text { mayoría relativa. }\end{array}$ \\
\hline $\begin{array}{c}\text { Partido Auténtico } \\
\text { de la Revolución } \\
\text { Mexicana }\end{array}$ & & $\begin{array}{l}12 \text { de diciembre } \\
\text { de } 1994\end{array}$ & $\begin{array}{c}\text { Obtuvo el } 0.55 \% \text { de la } \\
\text { votación emitida en la } \\
\text { elección Presidencial, el } \\
0.77 \% \text { en la de Senadores y el } \\
0.82 \% \text { en la de Diputados de } \\
\text { mayoría relativa. }\end{array}$ \\
\hline
\end{tabular}


Partidos Políticos Nacionales que han perdido su registro en el periodo 1991-2010

\begin{tabular}{|c|c|c|c|}
\hline $\begin{array}{l}\text { Partido Político } \\
\text { Nacional }\end{array}$ & $\begin{array}{l}\text { Fecha de } \\
\text { obtención de } \\
\text { registro }\end{array}$ & $\begin{array}{l}\text { Junta General } \\
\text { Ejecutiva (fecha } \\
\text { de sesión en la } \\
\text { que se declaró } \\
\text { la pérdida de } \\
\text { registro) }\end{array}$ & Motivo \\
\hline $\begin{array}{c}\text { Partido Demócrata } \\
\text { Mexicano }\end{array}$ & $\begin{array}{c}13 \text { de enero de } \\
1993\end{array}$ & $\begin{array}{l}12 \text { de diciembre } \\
\text { de } 1994\end{array}$ & $\begin{array}{l}\text { Obtuvo el } 0.28 \% \text { de la } \\
\text { votación emitida en la } \\
\text { elección Presidencial, el } \\
0.34 \% \text { en la elección de } \\
\text { Senadores y el } 0.43 \% \text { en la } \\
\text { elección de Diputados de } \\
\text { mayoría relativa }\end{array}$ \\
\hline $\begin{array}{c}\text { Partido Cardenista } \\
\text { (antes Partido del } \\
\text { Frente Cardenista } \\
\text { de Reconstrucción } \\
\text { Nacional) }\end{array}$ & & $\begin{array}{c}2 \text { de septiembre de } \\
1997\end{array}$ & $\begin{array}{c}\text { Obtuvo el } 1.12 \% \text { de la } \\
\text { votación emitida en la } \\
\text { elección de Senadores de } \\
\text { Representación Proporcional } \\
\text { y el } 1.09 \% \text { en la de Diputados } \\
\text { por ambos principios. }\end{array}$ \\
\hline $\begin{array}{l}\text { Partido Popular } \\
\text { Socialista }\end{array}$ & $\begin{array}{c}14 \text { de junio de } \\
1996\end{array}$ & $\begin{array}{c}2 \text { de septiembre de } \\
1997\end{array}$ & $\begin{array}{c}\text { Obtuvo el } 0.32 \% \text { de la } \\
\text { votación emitida en la } \\
\text { elección de Senadores de } \\
\text { Representación proporcional } \\
\text { y el } 0.33 \% \text { en la de Diuptados } \\
\text { por ambos principios. }\end{array}$ \\
\hline $\begin{array}{c}\text { Partido Demócrata } \\
\text { Mexicano }\end{array}$ & $\begin{array}{c}14 \text { de junio } \\
\text { de } 1996 \\
\text { (condicionado) }\end{array}$ & $\begin{array}{c}2 \text { de septiembre de } \\
1997\end{array}$ & $\begin{array}{c}\text { Obtuvo el } 0.64 \% \text { de la } \\
\text { votación emitida en la } \\
\text { elección de Senadores de } \\
\text { Representación Proporcional } \\
\text { y de Diputados por ambos } \\
\text { principios }\end{array}$ \\
\hline $\begin{array}{c}\text { Partido de Centro } \\
\text { Democrático }\end{array}$ & $\begin{array}{c}30 \text { de junio de } \\
1999\end{array}$ & $\begin{array}{c}30 \text { de agosto de } \\
2000\end{array}$ & $\begin{array}{c}\text { Obtuvo el } 0.55 \% \text { de la } \\
\text { votación emitida en la } \\
\text { elección Presidencial, el } \\
1.40 \% \text { en la de Senadores } \\
\text { de mayoría relativa, el } \\
1.39 \% \text { en la de Senadores de } \\
\text { representación proporcional } \\
\text { y el } 1.15 \% \text { en la de Diputados } \\
\text { por ambos principios. }\end{array}$ \\
\hline
\end{tabular}


Partidos Políticos Nacionales que han perdido su registro en el periodo 1991-2010

\begin{tabular}{|c|c|c|c|}
\hline $\begin{array}{l}\text { Partido Político } \\
\text { Nacional }\end{array}$ & $\begin{array}{l}\text { Fecha de } \\
\text { obtención de } \\
\text { registro }\end{array}$ & $\begin{array}{l}\text { Junta General } \\
\text { Ejecutiva (fecha } \\
\text { de sesión en la } \\
\text { que se declaró } \\
\text { la pérdida de } \\
\text { registro) }\end{array}$ & Motivo \\
\hline $\begin{array}{c}\text { Partido Auténtico } \\
\text { de la Revolución } \\
\text { Mexicana }\end{array}$ & $\begin{array}{c}30 \text { de junio de } \\
1999\end{array}$ & $\begin{array}{c}30 \text { de agosto de } \\
2000\end{array}$ & $\begin{array}{l}\text { Obtuvo el } 0.42 \% \text { de la } \\
\text { votación emitida en la } \\
\text { elección Presidencial, el } 0.74 \\
\text { en la de Senadores y el } 0.73 \\
\text { en la de Diputados por ambos } \\
\text { principios. }\end{array}$ \\
\hline Democracia Social & $\begin{array}{c}30 \text { de junio de } \\
1999\end{array}$ & $\begin{array}{c}30 \text { de agosto de } \\
2000\end{array}$ & $\begin{array}{c}\text { Obtuvo el } 1.57 \% \text { de la } \\
\text { votación emitida en la } \\
\text { elección Presidencial, el } \\
1.80 \% \text { en la de Senadores y el } \\
1.88 \% \text { en la de Diputados por } \\
\text { ambos principios. }\end{array}$ \\
\hline $\begin{array}{l}\text { Partido de } \\
\text { la Sociedad } \\
\text { Nacionalista }\end{array}$ & $\begin{array}{c}30 \text { de junio de } \\
1999\end{array}$ & $\begin{array}{c}29 \text { de agosto de } \\
2003\end{array}$ & $\begin{array}{l}\text { Obtuvo el } 0.27 \% \text { de la } \\
\text { votacióin emitida en la } \\
\text { elección de Diputados por } \\
\text { ambos principios. }\end{array}$ \\
\hline $\begin{array}{l}\text { Partido Alianza } \\
\text { Social }\end{array}$ & $\begin{array}{c}30 \text { de junio de } \\
1999\end{array}$ & $\begin{array}{c}29 \text { de agosto de } \\
2003\end{array}$ & $\begin{array}{l}\text { Obtuvo el } 0.74 \% \text { de la } \\
\text { votación emitida en la } \\
\text { elección de Diputados por } \\
\text { ambos principios. }\end{array}$ \\
\hline México Posible & $\begin{array}{c}03 \text { de julio de } \\
2002\end{array}$ & $\begin{array}{c}29 \text { de agosto de } \\
2003\end{array}$ & $\begin{array}{l}\text { Obtuvo el } 0.91 \text { de la votación } \\
\text { emitida en la elección de } \\
\text { Diputados de mayoría } \\
\text { relativa y el } 0.90 \text { en la de } \\
\text { Diputados de representación } \\
\text { proporcional }\end{array}$ \\
\hline $\begin{array}{l}\text { Partido Liberal } \\
\text { Mexicano (antes } \\
\text { Partido Liberal } \\
\text { Progresista) }\end{array}$ & $\begin{array}{c}03 \text { de julio de } \\
2002\end{array}$ & $\begin{array}{c}29 \text { de agosto de } \\
2003\end{array}$ & $\begin{array}{l}\text { Obtuvo el } 0.41 \% \text { de la } \\
\text { votaciíon emitida en la } \\
\text { elección de Diputados de } \\
\text { mayoría relativa y el } 0.40 \\
\text { en la de Diputados de } \\
\text { representación proporcional }\end{array}$ \\
\hline Fuerza Ciudadana & $\begin{array}{c}24 \text { de septiembre } \\
\text { de } 2002 \\
\text { (acatamiento) }\end{array}$ & $\begin{array}{c}29 \text { de agosto de } \\
2003\end{array}$ & $\begin{array}{l}\text { Obtuvo el } 0.46 \% \text { de la } \\
\text { votación emitida en la } \\
\text { elección de Diputados por } \\
\text { ambos principios. }\end{array}$ \\
\hline
\end{tabular}


Partidos Políticos Nacionales que han perdido su registro en el periodo 1991-2010

\begin{tabular}{|c|c|c|c|}
\hline $\begin{array}{c}\text { Partido Político } \\
\text { Nacional }\end{array}$ & $\begin{array}{c}\text { Fecha de } \\
\text { obtención de } \\
\text { registro }\end{array}$ & $\begin{array}{c}\text { Junta General } \\
\text { Ejecutiva (fecha } \\
\text { de sesión en la } \\
\text { que se declaró } \\
\text { la pérdida de } \\
\text { registro) }\end{array}$ & Motivo \\
\hline $\begin{array}{c}\text { Partido } \\
\text { Socialdemócrata } \\
\text { (Originalmente } \\
\text { Alternativa } \\
\begin{array}{c}\text { Socialdemócrata } \\
\text { y Campesina; } \\
\text { después Alternativa } \\
\text { Socialdemócrata) }\end{array}\end{array} \quad 14$ de julio de & 21 de agosto de & 2009 & $\begin{array}{c}\text { Obtuvo el 1.03\% de la } \\
\text { votación emitida en la } \\
\text { elección de Diputados por } \\
\text { ambos principios }\end{array}$ \\
\hline
\end{tabular}

Fuente: $w w w$.ife.org.mx. 